\title{
Rheological Behavior and Empirical Model of Simulated Foaming Slag
}

\author{
Kenta YAMASHITA, ${ }^{1)}$ Sohei SUKENAGA, ${ }^{2)}$ Michitaka MATSUO, ${ }^{3)}$ Noritaka SAITO ${ }^{1)}$ and \\ Kunihiko NAKASHIMA ${ }^{1) *}$
}

1) Department of Materials Science and Engineering, Kyushu University, 744, Motooka, Nishi-ku, Fukuoka, 819-0395 Japan. 2) Institute of Multidisciplinary Research for Advanced Materials, Tohoku University, 2-1-1, Katahira, Aoba-ku, Sendai, 9808577 Japan.

3) The Japan Research and Development Center for Metals, 1-5-11, Nishishinbashi, Minato-ku, Tokyo, 105-0003 Japan.

(Received on January 25, 2014; accepted on April 30, 2014)

\begin{abstract}
The slags and fluxes found in modern steelmaking convertors all contain finely dispersed gas phases, which are generated by the refining reaction used to decarburize the molten iron. The frothing effect that is often generated as a result of these gasses can often prove to be a fatal obstacle in the efficient operation of the converter. In the present study, a simulated slag foam was produced by dispersing $\mathrm{N}_{2}$ bubbles in silicone oil. The effect of varying the volume fraction and bubble size of the dispersed gas phase, the shear rate, and the viscosity of the liquid phase, was then systematically investigated by measuring the viscosity of the $\mathrm{N}_{2}$ bubble dispersed silicone oil with a rotating viscometer. This found that the relative viscosity is increased as the volume fraction of the gas phase is increased, ultimately transitioning from a Newtonian to pseudo-plastic fluid at higher gas phase rates. In addition, an empirical model for the viscosity of the slag foam was developed by modifying the Einstein-Roscoe equation, with this model capable of reproducing the variation in relative viscosity with various gas phase rates, shear rates, and bubble sizes.
\end{abstract}

KEY WORDS: viscosity; liquid/gas foam; non-newtonian fluid; shear rate; empirical modeling.

\section{Introduction}

As part of the steelmaking process, a massive amount of oxygen gas is blown into and/or onto the molten iron to react with carbon, which is the main impurity of molten iron produced in a blast furnace. The by-product of this is the generation of carbon monoxide gas, creating both a liquid and gas phase in the slag that presents a very real hazard of molten slag and steel projection. Accurate prediction of the behavior of multiphase gas/liquid slags is therefore essential to the safe and efficient operation of a converter.

Although it is essential to understand the physical and interfacial properties (e.g., viscosity, surface tension, etc.) of the liquid slag phase, as this determines the lifetime of any bubbles, ${ }^{1-4)}$ the viscosity of the multiphase gas/liquid slag also represents a critical parameter to gaining a greater understanding of the mass and heat transfer phenomena in the converter. Although a vast amount of viscosity data and models have been published and archived $^{5)}$ for slags as a single-phase liquid, very little data pertaining to multiphase gas/liquid slags has been reported thus far.

There have been previously published studies regarding the rheological behavior of multiphase gas/liquid fluids under ambient temperatures, with Sibree (1934) being the

* Corresponding author: E-mail: nakasima@zaiko.kyushu-u.ac.jp DOI: http://dx.doi.org/10.2355/isijinternational.54.2064 first to confirm and report that the viscosity of a liquid phase is increased by a vapor phase suspension. ${ }^{6)}$ Later, Uhira (1980) measured the viscosity of a silicone oil and bubble suspension with various volume fractions of the dispersed gas phase, ${ }^{7)}$ and similarly reported an increase in viscosity with a multiphase gas/liquid fluid. However, the practical application of such studies is limited by the fact that the rheological behavior of the slag foam generated in converters is affected by a number of different factors, including variation in the viscosity of the liquid phase, the size of the gas bubbles, the shear rate, etc.

In this study, an experimental apparatus for evaluating the viscosity of a multiphase gas/liquid fluid was constructed, and used to simulate the viscosity of slag foam under various experimental conditions using silicone oils as the liquid phase. An empirical equation is also proposed, which on the basis of the experimental values obtained, can accurately reproduce the viscosity of the slag foam.

\section{Experimental}

Figure 1 shows a schematic of the rotating viscometer used. This consists of an outer cylinder of acrylic pipe, and an inner rotating spindle from a commercially available viscometer (Brookfield digital viscometer DVII + ) The outer acrylic cylinder contains a porous bottom (Fine porous alumina, Krosaki Harima Corp.), which allows $\mathrm{N}_{2}$ gas bubbles 


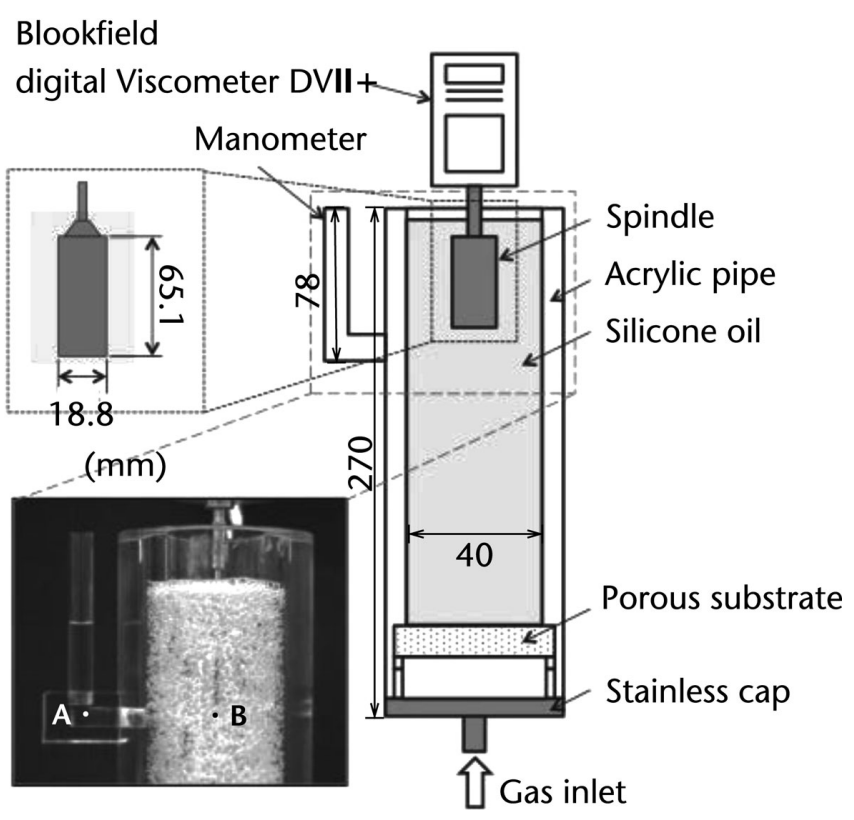

Fig. 1. Schematic illustration of the apparatus for viscosity measurement of foam at room temperature.

to be generated in the liquid phase silicone oil (KF-96, ShinEtsu Chemical Co., Ltd.) contained within. As previously mentioned, $\mathrm{CO}$ gas is generated in the actual converter process, but $\mathrm{N}_{2}$ gas exhibits quite similar thermophysical properties to $\mathrm{CO}$ gas, ${ }^{8-10)}$ as density, viscosity, specific heat, etc., because of their similarity in bonding nature. Thus, in the present study, the variation in apparent viscosity with different gas species can be negligibly small.

A manometer set on the sidewall of the outer cylinder provides the volume fraction of the gas phase dispersed in the silicone oil, a schematic diagram of which is shown in Fig. 1. The hydrostatic pressure at Point $\mathrm{A}\left(P_{A}\right)$ and Point B $\left(P_{B}\right)$ in Fig. 1 can be expressed by the following equations:

$$
\begin{gathered}
P_{A}=\rho_{\text {liquid }} g h_{\text {liquid }} \\
P_{B}=\rho_{\text {foam }} g h_{\text {foam }}
\end{gathered}
$$

where $\rho_{\text {liquid, }}, \rho_{\text {foam }}, g, h_{\text {liquid }}$, and $h_{\text {foam }}$ are the density of the liquid phase, the apparent density of the foam (multiphase gas/liquid fluids), acceleration due to gravity, the liquid phase level, and the foam level, respectively. When Points $\mathrm{A}$ and $\mathrm{B}$ are on the same level, their respective hydrostatic pressures must be equivalent. Therefore, $\rho_{\text {foam }}$ can be expressed by:

$$
\rho_{\text {foam }}=\rho_{\text {liquid }} \frac{h_{\text {liquid }}}{h_{\text {foam }}}
$$

Furthermore, $\rho_{\text {foam }}$ can be defined on the basis of the density of the gas phase $\left(\rho_{\text {gas }}\right)$, and the volume fraction of the gas phase $(\phi)$ as:

$$
\rho_{\text {foam }}=\rho_{\text {liquid }}(1-\phi)+\rho_{\text {gas }} \phi
$$

The value of $\phi$ is simply calculated by substituting Eq. (3) into Eq. (4), giving:

$$
\phi=\frac{\rho_{\text {liquid }}}{\rho_{\text {liquid }}-\rho_{\text {gas }}}\left(\frac{h_{\text {foam }}-h_{\text {liquid }}}{h_{\text {foam }}}\right)
$$

Table 1. Experimental conditions for the viscosity evaluation of $\mathrm{N}_{2}$ bubble dispersed silicone oil at room temperature.

\begin{tabular}{lcl}
\hline Volume fraction of bubbles & $\%$ & $10,20,30,40,50,60,(70),(80)$ \\
Viscosity of the liquid phase & $\mathrm{mPa} \cdot \mathrm{s}$ & $10,30,50,100,300,500,1000$ \\
Share rate & $\mathrm{s}^{-1}$ & $2.7,5.4,13,16,27$ \\
Pore size of porous alumina & $\mu \mathrm{m}$ & $0.1,1,3,30,50$ \\
\hline
\end{tabular}

The viscometer was calibrated using silicone oil standards for which the viscosity was already known (KF-96, Shin-Etsu Chemical Co., Ltd.), and the apparent viscosity of the multiphase gas/liquid fluids was then systematically measured under the various experimental conditions shown in Table 1. Mean bubble sizes were determined by calculating the average of the projected area diameters of over 50 bubbles from the side-view pictures of viscometer. Shear rate was calculated from the rotation speed used and the dimensions of the crucible and rod, as per the following equation: $^{11)}$

$$
\gamma=\frac{2 \omega}{1-\left(r_{i} / r_{0}\right)^{2}}
$$

where $\gamma, \omega, r_{0}$, and $r_{i}$ are the shear rate, angular rate, inner radius of the outer cylinder (crucible), and the radius of the inner cylinder (rod), respectively.

\section{Results and Discussion}

\subsection{Behavior of Bubbles in Silicone Oil}

Figure 2 depicts typical photographs and schematic illustrations of the flow behavior ${ }^{12,13)}$ of $\mathrm{N}_{2}$ gas bubbles in silicone oil. As can be seen in Fig. 2(a), the bubbles of $\mathrm{N}_{2}$ gas are uniformly dispersed throughout the silicone oil liquid phase in the acrylic cylinder. In contrast, Fig. 2(b) shows much larger bubbles of $\mathrm{N}_{2}$ gas being generated in a pulsating manner, which prevents the formation of stable and uniform slag foam suitable for viscosity measurement. The flow regimes revealed in Figs. 2(a) and 2(b) are categorized as bubble flow and slug flow, respectively. Note that the flow regime will shift from bubble to slug flow with an increase in the viscosity of the liquid phase or the gas flow rate. The rheological behavior of the multiphase gas/liquid fluid was therefore evaluated only under experimental conditions that ensured bubble flow. Table 2 summarizes the fluxional behavior (A: No Bubble, and B: Slug flow) of $\mathrm{N}_{2}$ bubble dispersed silicone oil at room temperature. Percentages show the maximum gas-phase rate at the given conditions.

\subsection{Rheological Behavior of Slag Foam}

Figure 3 shows the relative viscosity of $\mathrm{N}_{2}$ bubbles dispersed in silicone oil $(10 \mathrm{mPa} \cdot \mathrm{s})$ at various rotational speeds as a function of the gas phase rate. This provides an example of the apparent viscosity measurement of a multiphase gas/ liquid fluid, wherein the relative viscosity $\left(\eta / \eta_{\mathrm{L}}\right)$ is readily calculated by dividing the apparent viscosity of the multiphase fluid by the viscosity of the liquid phase (in this case, silicone oil). As can be seen in Fig. 3, the relative viscosity gradually increases with the volume fraction of the $\mathrm{N}_{2}$ gas phase, eventually reaching a value of around 2.5 at a gas phase rate of $55 \%$. With an increase in the gas phase rate 

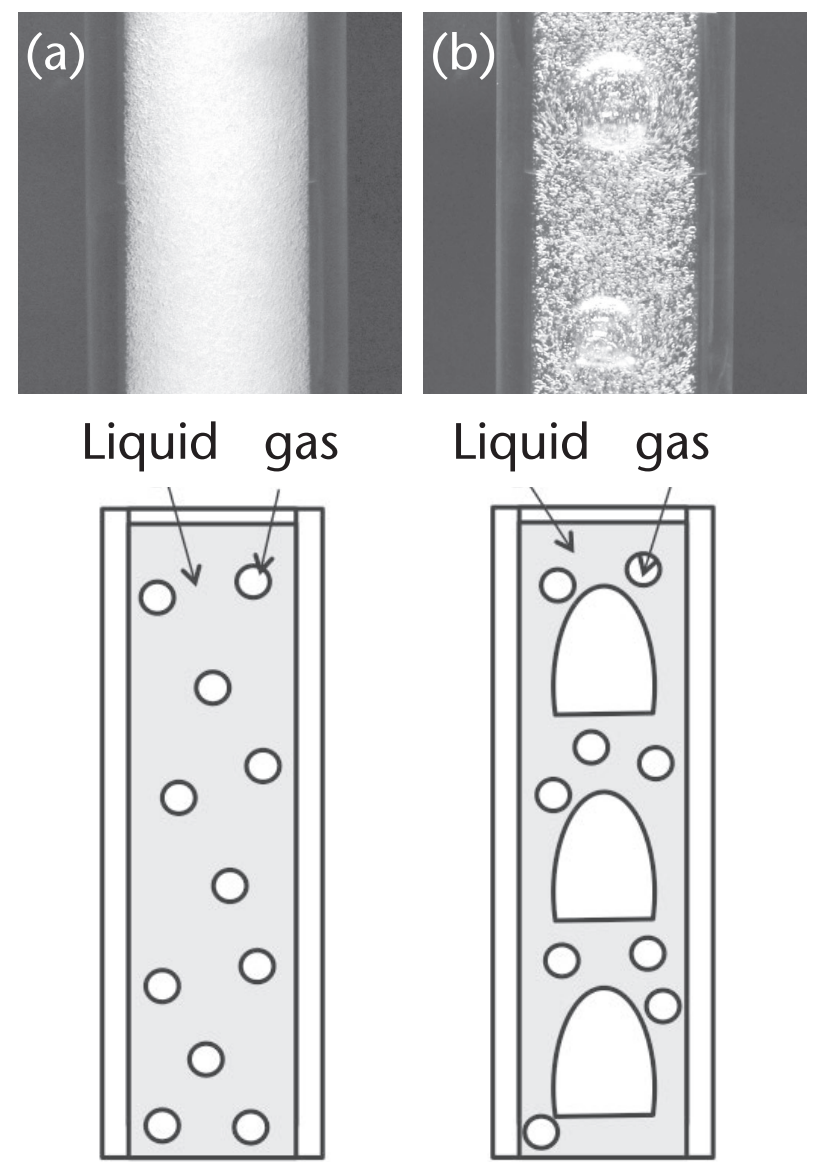

Fig. 2. Typical photograph and schematic illustration of flow behaviors of gas phase in silicone oil, (a) Bubble flow and (b) Slug flow.

Table 2. Summary of the fluxional behavior (-: No bubble, and S: Slug flow) of $\mathrm{N}_{2}$ bubble dispersed silicone oil at room temperature. Percentages show the maximum gas-phase rate at the given conditions.

\begin{tabular}{cccccc}
\hline pore size*/viscosity & $0.1 \mu \mathrm{m}$ & $1 \mu \mathrm{m}$ & $3 \mu \mathrm{m}$ & $30 \mu \mathrm{m}$ & $50 \mu \mathrm{m}$ \\
\hline $10 \mathrm{mPa} \cdot \mathrm{s}$ & - & $12 \%$ & $81 \%$ & $84 \%$ & $84 \%$ \\
$30 \mathrm{mPa} \cdot \mathrm{s}$ & - & $12 \%$ & $57 \%$ & $60 \%$ & $69 \%$ \\
$50 \mathrm{mPa} \cdot \mathrm{s}$ & - & $11 \%$ & $67 \%$ & $76 \%$ & $59 \%$ \\
$100 \mathrm{mPa} \cdot \mathrm{s}$ & - & - & $\mathrm{S}$ & $44 \%$ & $37 \%$ \\
$300 \mathrm{mPa} \cdot \mathrm{s}$ & - & - & $\mathrm{S}$ & $\mathrm{S}$ & $37 \%$ \\
$500 \mathrm{mPa} \cdot \mathrm{s}$ & - & - & $\mathrm{S}$ & $\mathrm{S}$ & $38 \%$ \\
$1000 \mathrm{mPa} \cdot \mathrm{s}$ & - & - & $\mathrm{S}$ & $\mathrm{S}$ & $30 \%$ \\
\hline
\end{tabular}

* pore size of porous alumina

beyond this point (i.e., $60 \%$ or more), the relative viscosity rapidly increases, reaching a maximum of more than 20 at a gas phase rate of $80 \%$. This drastic increase in the relative viscosity indicates that an $80 \%$ gas phase rate creates a multiphase gas/fluid that is roughly 20 times more viscous than its liquid phase alone.

At higher gas-phase volume fractions, the relative viscosity was found to be more dependent on the rotational speed of the spindle. In contrast, this dependence was negligible at lower gas phase rates. Furthermore, for a given gas phase rate, the relative viscosity was found to higher with a lower rotational speed, which is a characteristic behavior of non-

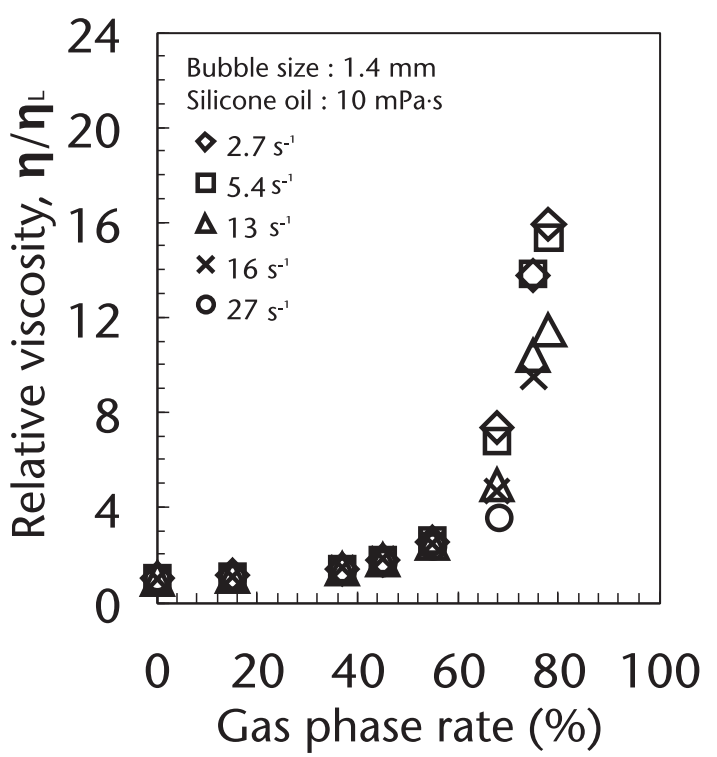

Fig. 3. Relative viscosity of $\mathrm{N}_{2}$ bubbles dispersed silicone oil $(10 \mathrm{mPa} \cdot \mathrm{s})$ as a function of gas phase rate with various rotational speeds of the spindle.

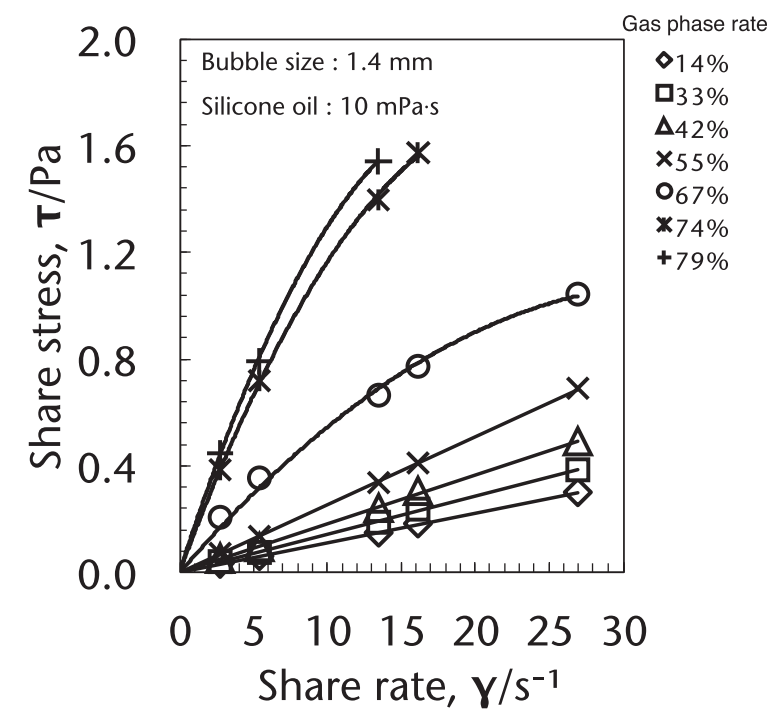

Fig. 4. Shear stress as a function of shear rate which was calculated from apparent viscosity of $\mathrm{N}_{2}$ bubbles dispersed silicone oil, rotational speed of the spindle, and the dimensions of viscometer.

Newtonian fluids.

Figure 4 demonstrates the variation in shear stress with shear rate, with the latter being estimated by multiplying the apparent viscosity by the shear rate, as-calculated from the dimensions of the viscometer and rotational speed of the spindle. With a relatively low gas phase rate $(\sim 55 \%)$, the estimated shear stress increases linearly with shear rate and eventually crosses the origin, which is characteristic Newtonian fluid behavior. On the other hand, at a higher gas phase rate $(\sim 67 \%)$, the shear stress forms a convex upward curve with an increase in shear rate, which is typical behavior of a pseudo-plastic non-Newtonian fluid. ${ }^{14)}$

Figures 5-7 shows the relative viscosity of $\mathrm{N}_{2}$ bubbles dispersed in silicone oils of various viscosities $(30,50$, and $300 \mathrm{mPa} \cdot \mathrm{s}$, respectively) as a function of the gas phase rate with various spindle rotation speeds. As can be seen in Fig. 


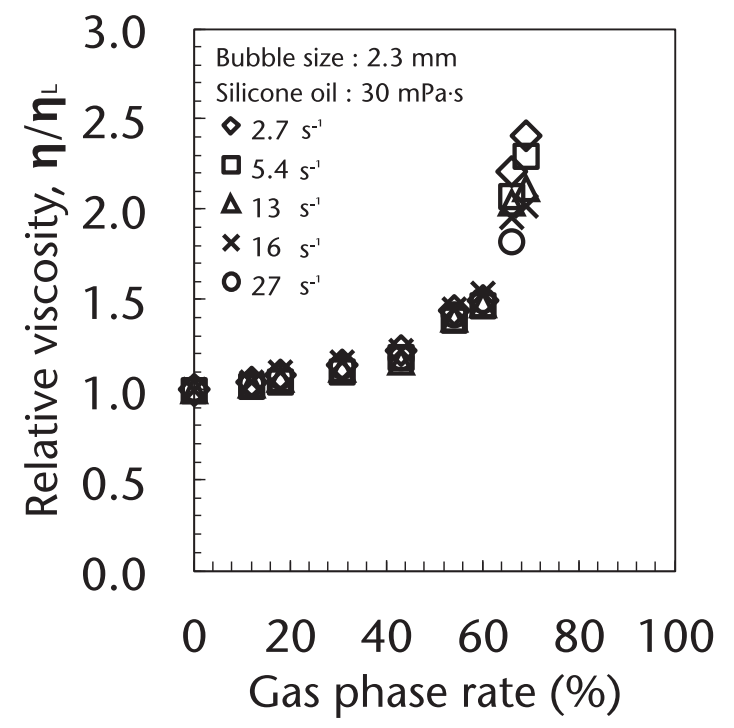

Fig. 5. Relative viscosity of $\mathrm{N}_{2}$ bubbles dispersed silicone oil $(30 \mathrm{mPa} \cdot \mathrm{s})$ as a function of gas phase rate with various rotational speeds of the spindle.

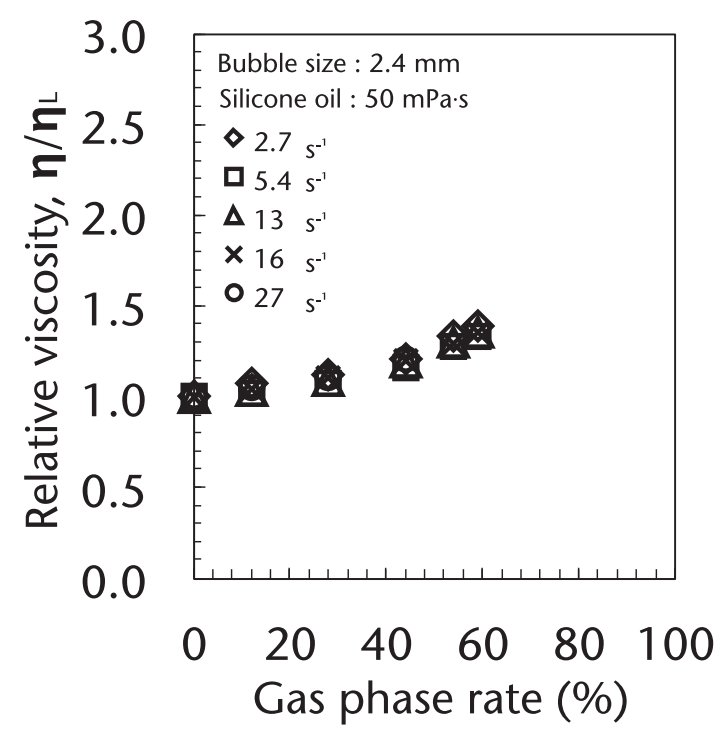

Fig. 6. Relative viscosity of $\mathrm{N}_{2}$ bubbles dispersed silicone oil $(50 \mathrm{mPa} \cdot \mathrm{s})$ as a function of gas phase rate with various rotational speeds of the spindle.

5 , for a silicone oil with a viscosity of $30 \mathrm{mPa} \cdot \mathrm{s}$ the relative viscosity increases similarly to Fig. 3 , reaching 1.5 at a gas phase rate of 55\%. In the case of higher gas phase rates (i.e., $60 \%$ or more), the sharp increase in the relative viscosity indicates a transition from a Newtonian to non-Newtonian (pseudo-plastic) fluid, reaching a value of 2.5 at a gas phase rate of $70 \%$. However, as in the case shown in Fig. 5, the relative viscosity was found to be smaller still when using a silicone oil with a viscosity of $10 \mathrm{mPa} \cdot \mathrm{s}$. This can mainly be attributed to the smaller size of the dispersed $\mathrm{N}_{2}$ bubbles in the lower viscosity oil when compared to those in a $30 \mathrm{mPa} \cdot \mathrm{s}$ silicone oil. This tendency for larger bubbles with higher viscosity became more evident among the higher viscosity silicone oils tested. In the case of silicone oils with viscosities of 50 and $100 \mathrm{mPa} \cdot \mathrm{s}$ for example, as shown in Figs. 6 and 7, the increase in relative viscosity with gas phase rate was found to be more modest and a transition to

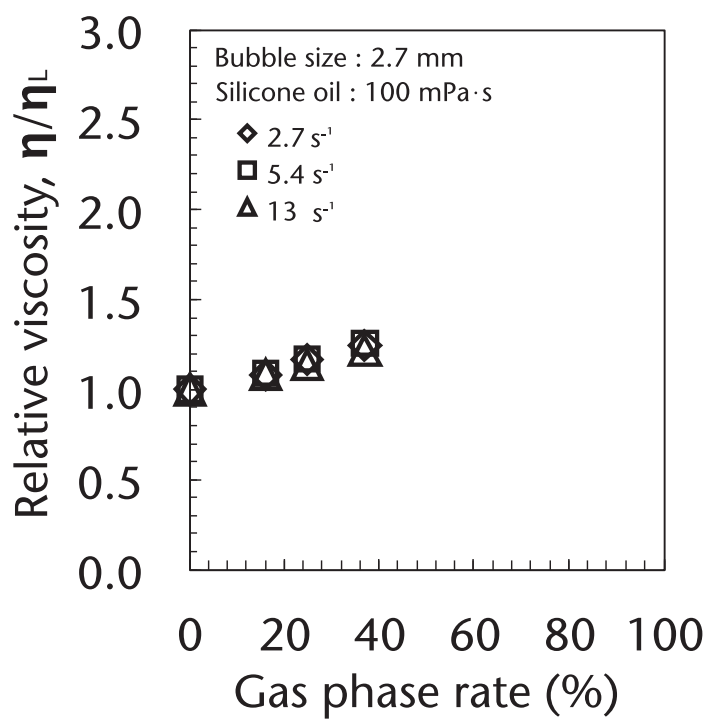

Fig. 7. Relative viscosity of $\mathrm{N}_{2}$ bubbles dispersed silicone oil $(100 \mathrm{mPa} \cdot \mathrm{s})$ as a function of gas phase rate with various rotational speeds of the spindle.

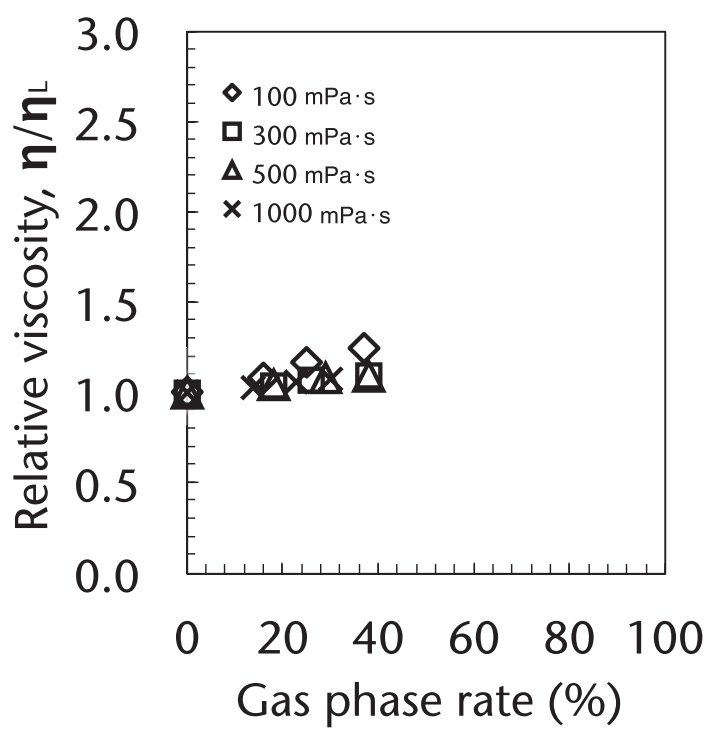

Fig. 8. Relative viscosity of $\mathrm{N}_{2}$ bubbles dispersed silicone oil $(100-1000 \mathrm{mPa} \cdot \mathrm{s})$ as a function of gas phase rate at $10 \mathrm{rpm}$ of the rotational speed of the spindle.

a pseudo-plastic fluid was not observed with the gas volume fractions that were achieved in the experimental conditions of the present study.

Figure 8 illustrates the variation in the relative viscosity of 300-1 $000 \mathrm{mPa} \cdot \mathrm{s}$ silicone oils with dispersed gas bubbles averaging $2.6 \mathrm{~mm}$ in diameter, and at a spindle speed of $10 \mathrm{rpm}$. This supports the aforementioned observations, i.e., that higher viscosity silicone oils minimize the variation in the relative viscosity, with a relative viscosity of around 1.1 even at a gas phase rate as high as $40 \%$.

\subsection{Empirical Modeling of Slag Foam Viscosity}

Various equations for the estimation of viscosity in multiphase fluids have been proposed over the last century. Among these, a viscosity equation for suspensions as a function of the volume fraction of a dispersed solid phase was first announced by Einstein in 1906, as shown in (Eq. (7)). ${ }^{15}$ ) 
However, this equation of Einstein's is an expression that is only applicable to spherical particles within a dispersed system. It was nearly half a century later that expansion to higher volume fractions of the secondary phase gained the attention of numerous researchers. ${ }^{16-25)}$ Of these, the Einstein-Roscoe relationship shown in (Eq. (8) $)^{26)}$ is considered to be one of the most applicable models.

$$
\begin{gathered}
\frac{\eta}{\eta_{0}}=1+2.5 \phi \\
\frac{\eta}{\eta_{L}}=(1-a \phi)^{-n}
\end{gathered}
$$

where $\eta, \eta_{L}, \phi, a$, and $n$ are the apparent viscosity of the multiphase fluid, viscosity of the liquid phase, volume fraction of a dispersed secondary phase, and constants, respectively. Here, the a-coefficient expresses aggregational state of the dispersed secondary phase in matrix fluid and increases with agglomeration degree, thus the a-coefficient can be assumed as unity, and the n-coefficient can be assumed as 2.5 for spherical particles dispersed system. ${ }^{26}$

Equations applicable to a multiphase gas/liquid fluid have also been previously proposed based on the capillary number ${ }^{27,28)}$ of Frankel and Acrivos (Eq. (9)), ${ }^{29)}$ and Han and King (Eq. (10)), ${ }^{30)}$ as follows:

$$
\begin{aligned}
& \frac{\eta}{\eta_{L}}=\frac{1+\left(\frac{5}{6} \mathrm{Ca}\right)^{2}+\phi\left(1-\frac{12}{5} \mathrm{Ca}^{2}\right)}{1+\left(\frac{5}{6} \mathrm{Ca}\right)^{2}} \\
& \frac{\eta}{\eta_{L}}=\frac{1+\left(\frac{6}{5} \mathrm{Ca}\right)^{2}\left(1+\frac{20}{3} \phi\right)(1+4 \phi)}{1+\left(\frac{6}{5} \mathrm{Ca}\right)^{2}\left(1+\frac{20}{3} \phi\right)^{2}}\left(1+\phi+\frac{5}{2} \phi^{2}\right) \ldots
\end{aligned}
$$

The capillary number $\mathrm{Ca}$ can be simply calculated from the following equation:

$$
\mathrm{Ca}=\frac{\eta_{L} U}{\sigma_{L}}=\frac{\eta_{L} \gamma d}{\sigma_{L}}
$$

where $\eta_{\mathrm{L}}, U, \sigma_{L}$, and $d$ are the viscosity of the liquid phase, characteristic speed, surface tension of the liquid phase, and the bubble diameter of the dispersed gas phase, respectively. In addition, Hinata et al. have also proposed an equation based on a function of the capillary number as follows ${ }^{17)}$

$$
\frac{\eta}{\eta_{L}}=\left(\frac{0.45+1.3 \phi}{\mathrm{Ca}^{\frac{1}{6}}}\right) \phi
$$

Comparison was made between the experimental values obtained in the present study with those calculated by the various viscosity equations described above in order to evaluate their feasibility. As shown in Figs. 9 and 10, no one equation proved capable of consistently reproduce the experimental values obtained, but instead produced values that were notably higher.

The Einstein-Roscoe equation was selected to expand its applicability to a wider range of gas volume fractions, liquid phase viscosities and shear rates. It has previously been sug-

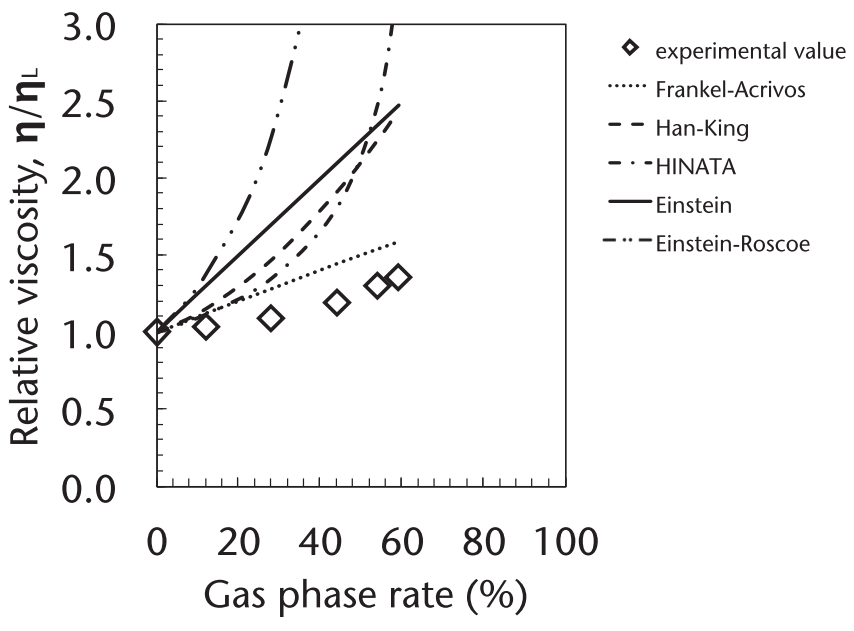

Fig. 9. Typical comparisons of viscosity equations for gas-phase dispersed fluid with the experimental values at the present study ( $50 \mathrm{mPa} \cdot \mathrm{s}$ of silicone oil at $\left.2.7 \mathrm{~s}^{-1}\right)$.

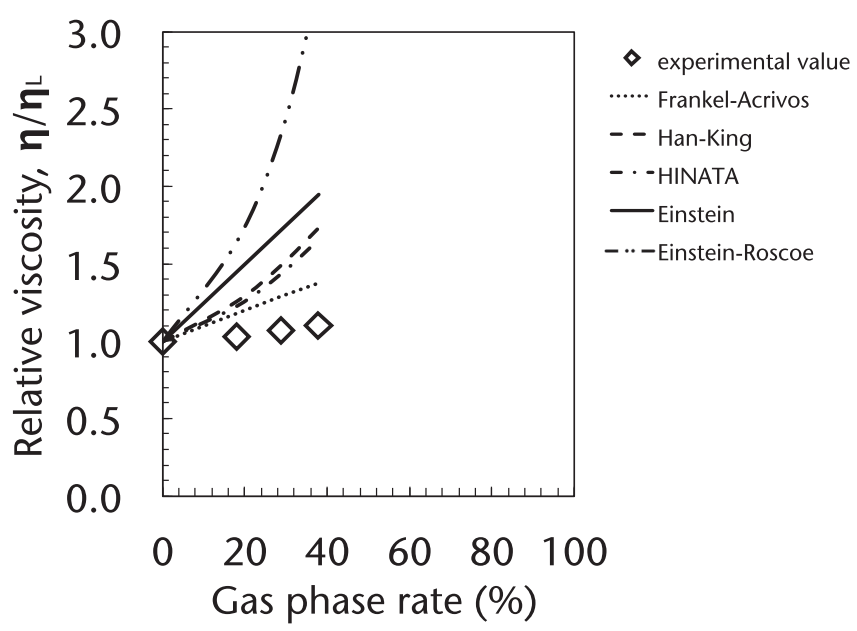

Fig. 10. Typical comparisons of viscosity equations for gas-phase dispersed fluid with the experimental values at the present study $\left(500 \mathrm{mPa} \cdot \mathrm{s}\right.$ of silicone oil at $\left.2.7 \mathrm{~s}^{-1}\right)$.

gested by Lejeune ${ }^{31)}$ that the n-coefficient of this equation is strongly associated with the electrical, thermal, and geometric properties of the dispersed secondary phases. Additionally, the a-coefficient can be assumed as unity. ${ }^{28)}$ Therefore, $\phi$ is the only independent variable in the Einstein-Roscoe equation, it can be defined as a function of other experimental variables such as the viscosity of the liquid phase, shear rate and bubble size. An empirical equation for the viscosity of a slag foam under various conditions can therefore be developed; however, as shown in Eq. (8), this $\mathrm{n}$-coefficient is a dimensionless number. Consequently, the capillary numbers were calculated from a combination of the experimental conditions employed in the present study, and their relationship to the n-coefficient was estimated from the apparent viscosity of the slag foam.

Figure 11 shows this n-coefficient as a function of the capillary number, with an exponential decrease with increasing capillary number clearly observable. A regression curve was obtained in accordance with the relationship shown in Fig. 11, and can be expressed as:

$$
n=0.148 \mathrm{Ca}^{-0.371}
$$




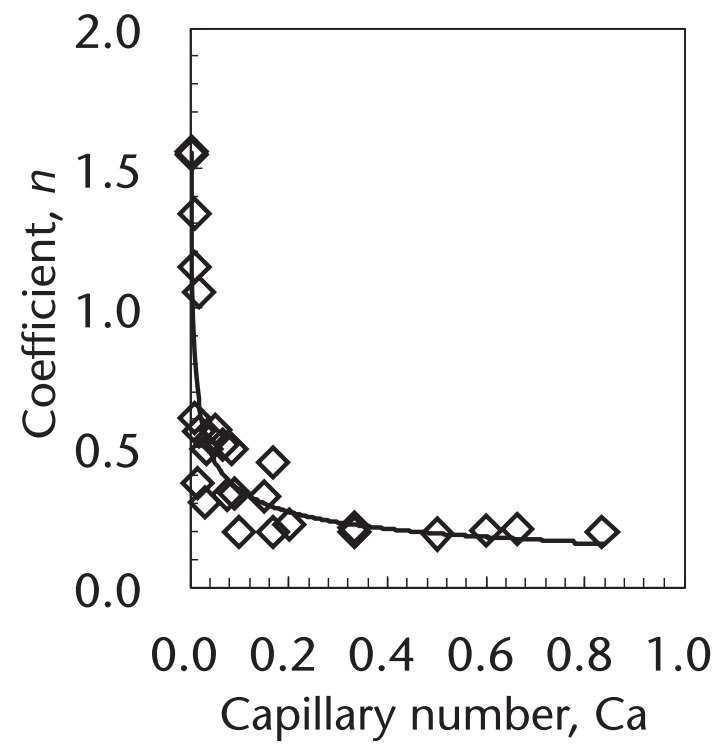

Fig. 11. Coefficient $\mathrm{n}$ of Einstein-Roscoe's equation as function of capillary number $\mathrm{Ca}$ calculated from the experimental conditions at the present study.

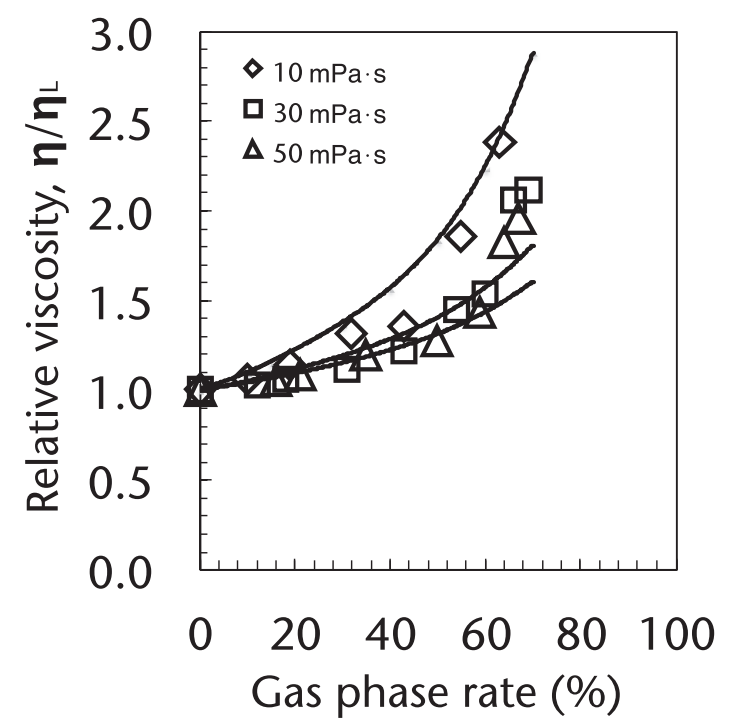

Fig. 12. Typical comparisons of the viscosity equation proposed at the present study and based on the Einstein-Roscoe's equation for gas-phase dispersed fluid with the experimental values at the study $(10-50 \mathrm{mPa} \cdot \mathrm{s}$ of silicone oil at $\left.13 \mathrm{~s}^{-1}\right)$.

This indicates that the relative viscosity will demonstrate a similar exponential increase as a result of the steep increase in the n-coefficient with decreasing capillary number.

Figures 12 and 13 depict typical comparisons of this proposed viscosity equation with the experimental values obtained. This confirms that the modified Einstein-Roscoe equation developed by this study can successfully reproduce experimental values across a wide range of rheological conditions. Figure 14 extends this comparison to the experimental values of Uhira's study. ${ }^{7)}$ Once again, the calculated values can be seen to agree well with the experimental values for all shear rates, at least in the lower $(20 \%)$ gas-phase volume fraction. However, with higher gas volume fractions, the experimental values were found to be much greater than those estimated by the modified Einstein-Roscoe

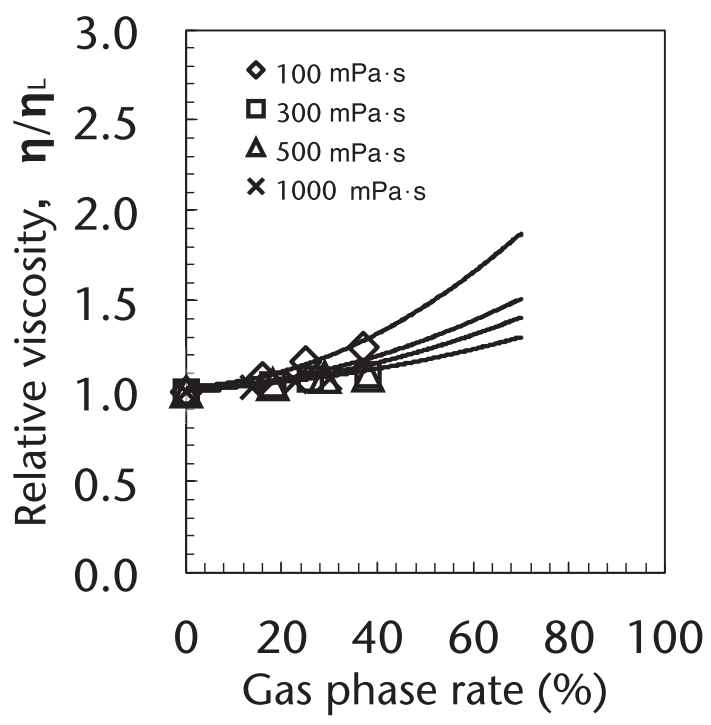

Fig. 13. Typical comparisons of the viscosity equation proposed at the present study and based on the Einstein-Roscoe's equation for gas-phase dispersed fluid with the experimental values at the study $(100-1000 \mathrm{mPa} \cdot \mathrm{s}$ of silicone oil at $13 \mathrm{~s}^{-1}$ ).

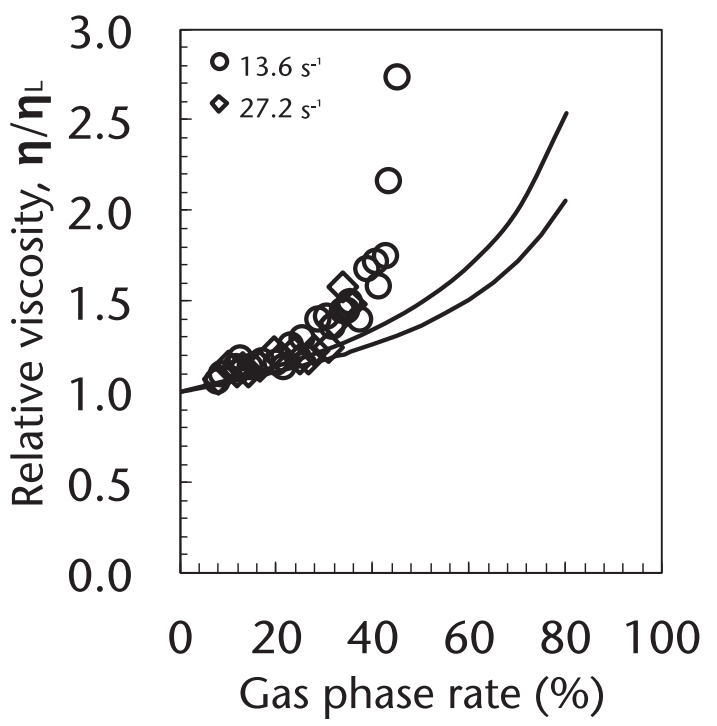

Fig. 14. Comparison of the viscosity equation proposed at the present study and based on the Einstein-Roscoe's equation for gas-phase dispersed fluid with the experimental values of Uhira's study.

equation. This variation is believed to be mainly attributed to the finer size of the dispersed bubbles.

\section{Conclusion}

An experimental apparatus for evaluating the viscosity of a multiphase gas/liquid fluid was constructed, and used to evaluate the viscosity of a slag foam simulated by silicone oils containing $\mathrm{N}_{2}$ gas under various experimental conditions considered likely to encompass those of the steelmaking converter process. The major findings of this study can be summarized as follows:

(1) The apparent viscosity of a multiphase gas/liquid fluid with a dispersed $\mathrm{N}_{2}$ gas-phase volume fraction of up to $85 \%$ was successfully measured using a viscometer with 
a porous alumina base.

(2) For low viscosity (less than $30 \mathrm{mPa} \cdot \mathrm{s}$ ) silicone oils, the relative viscosity was found to increase with the gas phase rate, transitioning from a Newtonian to a pseudo-plastic fluid at a gas phase rate of around $60 \%$.

(3) In the case of higher viscosity (over $50 \mathrm{mPa} \cdot \mathrm{s}$ ) silicone oils, a modest increase in relative viscosity with gas phase rate was observed, with no discernible transition in behavior.

(4) An empirical model for determining the viscosity of a slag foam was developed by modifying the Einstein-Roscoe equation, and was found to be capable of reproducing the variation in relative viscosity with various gas phase rates, shear rates, and bubble sizes.

\section{REFERENCES}

1) E. J. Jung and D. J. Min: Steel Res. Int., 83 (2012), 705.

2) H. Kania, K. Nowacki and T. Lis: Metalurgija, 52 (2013), 204.

3) A.Warczok and T. A. Utigard: Can. Metall. Q., 33 (1994), No. 3, 205.

4) Y. Zhang and R. J. Fruehan: Metall. Trans., 26B (1995), No. 4, 803.

5) K. C. Mills: Slag Atlas, 2nd Ed., Verlag Stahleisen GmbH, Düsseldorf, (1995), 349.

6) J. O. Sibree: Trans. Far. Soc., 30 (1934), 325.

7) K. Uhira: Bull. Earthq. Res. Inst., 55 (1980), 857

8) G. L. Chierici and A. Paratella: AlChE J., 15 (1969), 786.

9) R. D. Goodwin: J. Phys. Chem. Ref. Data, 14 (1985), 849.
10) R. T. Jacobsen, R. B. Stewart and M. Jahangiri: J. Phys. Chem. Ref. Data, 15 (1986), 735.

11) K. Ozaki: Rheology no Sekai, Kougyoucyousakai, Tokyo, (2004), 49.

12) H. Enwald, E. Peirano and A. E. Almstedt: Int. J. Multiphase Flow, 22 (1966), 21.

13) N. Kantarci, F. Borak and K. O. Ulgen: Process Biochem., 40 (2005), 2263.

14) P. Tisne, F. Aloui and L. Doubliez: Int. J. Multiphase Flow, 29 (2003), 841.

15) A. Einstein: Ann. Physik., 19 (1906), 289.

16) G. I. Taylor: Proc. R. Soc. London Ser. A, 138 (1932), 41.

17) S. Hinata, O. Kuga, K. Kobayashi and T. Inoue: Trans. Jpn. Soc. Mech. Eng., 14 (1971), 951.

18) M. Wu, M. E. Sullivan and D. J. Yee: Collpid. Surf., 12 (1984), 375.

19) D. J. Stein and F. J. Spera: J. Volcanol. Geoth. Res., 49 (1992), 157.

20) M. Iguchi and Z. Morita: ISIJ Int., 32 (1992), 857.

$21)$ D. J. Stein and F. J. Spera: J. Volcanol. Geoth. Res., 113 (2002), 243.

$22)$ E. W. Llewellin, H. M. Mader and S. D. R. Wilson: Proc. R. Soc. London Ser. A, 458 (2002), 987.

$23)$ N. Bagdassarov and H. Pinkerton: J. Volcanol. Geoth. Res., 3002 (2003), 1.

24) H. Oiwa, Y. Murai and F. Yamamoto: Trans. Jpn. Soc. Mech. Eng., 70 (2004), 48.

25) S. Wang and A. F. Clarens: Water Resour. Res., 48 (2011), 1.

26) R. Roscoe: Br. J. Appl. Phys., 3 (1952), 267.

27) M. Manga, J. Castro, K. V. Cashman and M. Loewenberg: J. Volcanol. Geoth. Res., 87 (1998), 15.

28) A. C. Rust and M. Manga: J. Non-Newtonian Fluid Mech., 104 (2002), 53.

29) N. A. Frankel and A. Acrivos: J. Fluid Mech., 44 (1970), 65

30) C. D. Han and R. G. King: J. Rheol., 24 (1980), 213.

31) A. M. Lejeune and P. Richet: J. Geo. Res., 100 (1995), 4215. 